\title{
Erratum to: The Concept of Health Literacy
}

\author{
Peter J. Schulz
}

Erratum to:

Chapter 5 in: A. Zeyer and R. Kyburz-Graber (eds.), Science |

Environment | Health: Towards a Renewed Pedagogy

for Science Education, https://doi.org/10.1007/978-90-481-3949-1_5

Dr. Kent Nakamoto should not be named as author to this chapter, as he did not fulfill all authorship criteria.

The extract of Kaldjian on p. 76 starting with "practical wisdom, acquired over time..." should have been placed in quotation marks. An institutional investigation by the Università della Svizzera italiana, Lugano, Switzerland found that this extract was not cited appropriately, but that any other overlap in this chapter was not significant. 